\title{
Carnitine palmitoyl transferase II deficiency, myopathic form
}

INSERM

\section{Source}

INSERM. (1999). Orphanet: an online rare disease and orphan drug data base. Carnitine palmitoyl transferase // deficiency, myopathic form. ORPHA:228302

The myopathic form of carnitine palmitoyltransferase II (CPT II) deficiency, an inherited metabolic disorder that affects mitochondrial oxidation of long chain fatty acids (LCFA), is the most common and the least severe form of CPT II deficiency (see this term). 